\title{
Meridionally tilted ice cloud structures in the tropical upper troposphere as seen by CloudSat
}

\author{
J. Gong ${ }^{1,2}$, D. L. Wu' ${ }^{2}$ and V. Limpasuvan ${ }^{3}$ \\ ${ }^{1}$ University Space Research Association, Columbia, MD, USA \\ ${ }^{2}$ Climate and Radiation Branch, MC 613.2, NASA/Goddard Space Flight Center, Greenbelt, MD, USA \\ ${ }^{3}$ School of Coastal and Marine Systems Science, Coastal Carolina University, Conway, SC, USA \\ Correspondence to: J. Gong (jie.gong@ nasa.gov)
}

Received: 3 September 2014 - Published in Atmos. Chem. Phys. Discuss.: 26 September 2014

Revised: 24 April 2015 - Accepted: 15 May 2015 - Published: 9 June 2015

\begin{abstract}
It remains challenging to quantify global cloud properties and uncertainties associated with their impacts on climate change because of our poor understanding of cloud three-dimensional (3-D) structures from observations and unrealistic characterization of 3-D cloud effects in global climate models (GCMs). In this study we find cloud 3-D effects can cause significant error in cloud ice and radiation measurements if it is not taken into account appropriately.

One of the cloud 3-D complexities, the slantwise tilt structure, has not received much attention in research and even less has been reported considering a global perspective. A novel approach is presented here to analyze the ice cloud water content (IWC) profiles retrieved from CloudSat and a joint radar-lidar product (DARDAR). By integrating IWC profiles along different tilt angles, we find that uppertroposphere (UT) ice cloud mass between 11 and $17 \mathrm{~km}$ is tilted poleward from active convection centers in the tropics $\left[30^{\circ} \mathrm{S}, 30^{\circ} \mathrm{N}\right]$. This systematic tilt in cloud mass structure is expected from the mass conservation principle of the Hadley circulation with the divergent flow of each individual convection/convective system from down below, and its existence is further confirmed from cloud-resolving-scale Weather Research and Forecasting (WRF) model simulations. Thus, additive effects of tilted cloud structures can introduce $5-20 \%$ variability by its nature or produce errors to satellite cloud/hydrometeor ice retrievals if simply converting it from slant to nadir column. A surprising finding is the equatorward tilt in middle tropospheric $(5-11 \mathrm{~km})$ ice clouds, which is also evident in high-resolution model simulations but not in coarse-resolution simulations with cumulus parameterization. The observed cloud tilt structures are intrin-
\end{abstract}

sic properties of tropical clouds, producing synoptic distributions around the Intertropical Convergence Zone (ITCZ). These findings imply that current interpretations based on over-simplified cloud vertical structures could lead to considerable cloud measurement errors and have a subsequent impact on understanding cloud radiative, dynamical and hydrological properties.

\section{Introduction}

Understanding and predicting climate changes requires accurate measurements of Earth's radiation budget. Due to its large variability in space and time, the cloud radiative effect (CRE) poses arguably the greatest difficulty in estimating the radiation budget balance at both the top of the atmosphere (TOA) and surface. Complexities in cloud three-dimensional structures, in particular, are one of the primary sources of the uncertainty and difficulty, which affect satellite cloud observations as well as CRE calculations in global climate models (GCMs).

Cloud 3-D effects manifest themselves in multiple forms: cloud is visibly irregular and the internal mass structures are also inhomogeneous. The cloud vertical structures are difficult to resolve in passive satellite observations. Subsequently, they are significantly simplified in GCMs. Oversimplified or improper treatment of the cloud 3-D structure increases the uncertainties or generates additional biases of satellite cloud property retrievals (Marshak et al., 2006), GCM simulations of cloud fields (Cahalan et al., 1994) and atmospheric constituent retrievals (Ming and Zhang, 2014). 
As one key vertical aspect of cloud 3-D structure, cloud slantwise tilt is inherently linked to cloud thermodynamics and gravity waves coupled with heating profiles. Systematic cloud tilt structures can have profound impacts on cloud remote sensing and radiation calculations. For example, they partially account for the anisotropy of the cloud radiative forcing (Fu et al., 2000; Gong and $\mathrm{Wu}, 2013$ ) and modulate the hydrological cycle (Naud et al., 2010). Neglecting or misrepresenting the cloud tilt induces additional biases in satellite retrieval of cloud properties (e.g., Hong et al., 2005) and increases uncertainty of model CRE estimation (e.g., Li and Barker, 2002). In GCM, cloud slantwise tilt is tied to the "overlap" parameter, which is assumed to be "maximum-random" globally in most GCMs to achieve the desired cloud fraction or radiation balance. However, studies have shown that this parameter has large geographical and temporal variations around the globe (Oreopoulos et al., 2012; Yuan and Oreopoulos, 2013), which implies that the prevailing assumption in GCMs needs to be improved and could be constrained by satellite observations.

Very few global surveys have been published on cloud tilt structures so far. It is difficult for passive sensors because of their coarse vertical/horizontal resolutions and variable penetration depths, yielding ambiguous information about cloud internal structures. Nevertheless, Gong and Wu (2011, 2013) were able to derive cloud tilt statistics of the upper troposphere cloud in the zonal direction using radiance data from NASA's Aqua Atmospheric Infrared Sounder (AIRS) and NOAA's Microwave Humidity Sounder (MHS). Groundbased radar observations, plotted in the time series domain, often show tilt structures, which are however contaminated by rainfall signals from time to time (Huang et al., 2012).

In this study, we make a novel use of polar-orbiting CloudSat Cloud Profiling Radar (CPR) data to characterize global cloud tilt structures in the meridional direction. CloudSat provides unprecedented quality of high-resolution ice water content (IWC) measurements for investigating cloud internal structures in the upper troposphere (UT) (Protat et al., 2009). By integrating CloudSat IWC along different slant paths, we find that ice clouds at height greater than $11 \mathrm{~km}$ are systematically tilted poleward from active convection centers in the tropics $\left[30^{\circ} \mathrm{S}, 30^{\circ} \mathrm{N}\right]$. The observed cloud tilt structures resemble the divergent flow at the top of deep convection and convergence below in the tropical branch of the Hadley circulation.

\section{Data sets, model and methodology}

Launched in April 2006 into a sun-synchronous orbit, CloudSat has the same equator crossing time $(\sim 01: 30 / 13: 30$ local time) on the ascending/descending as other A-Train constellation members. CloudSat CPR, a $94 \mathrm{GHz}$ nadir-scan radar, returns the aggregation of 600 pulses every $0.16 \mathrm{~s}$ during which the platform travels $1.1 \mathrm{~km}^{1}$. The CloudSat IWC product from 2B-CWC-RO V008 has a vertical resolution of $\sim 0.25 \mathrm{~km}$ and horizontal resolution of $\sim 1.1 \mathrm{~km}$. Despite having been validated against aircraft measurements and many other independent observations (Protat et al., 2009; Wu et al., 2009), the CloudSat IWC product still has some known issues. Thin cirrus clouds are normally below its detection threshold, and the W-band radar tends to suffer from attenuation and/or multiple-scattering below $9 \mathrm{~km}$ when clouds are heavily precipitating (Protat et al., 2009). Austin et al. (2009) estimated this IWC product uncertainty of up to $\sim 40 \%$, while Eliasson et al. (2013) pointed out that the error could be much larger in mixed-phase clouds as well as in thin ice cloud. Since the mass of upper-level tropical ice cloud is the main focus of this paper, results would be least impacted by the large uncertainty associated with mixed-phase cloud and thin ice cloud. CALIPSO's (Cloud-Aerosol Lidar and Infrared Pathfinder Satellite Observation) Cloud-Aerosol Lidar with Orthogonal Polarization (CALIOP) is a great complement for filling in the thin ice cloud part of the picture missed by CloudSat. A recently published joint IWC retrieval product (DARDAR) combining CloudSat-CALIPSOMODIS (Moderate Resolution Imaging Spectroradiometer) observations shows robust consistency with CloudSat IWC without losing the signal from thin ice clouds (Delanoe et al., 2010, 2013; Eliasson et al., 2013). Since DARDAR retrieval is dominated by CloudSat input when the ice water path (IWP) exceeds $80 \mathrm{~g} \mathrm{~m}^{-2}$, we do not expect the two results to be significantly different. DARDAR is used as a complement in this study rather than as independent evidence. Due to the limitation of the CloudSat IWC product, this study will focus primarily on ice clouds above $9 \mathrm{~km}$. Nonetheless, we will briefly address the tilt characteristic of ice clouds between $5 \mathrm{~km}$ (roughly the freezing height) and $9 \mathrm{~km}$ as cloud tilt structure continuously evolves with height.

Figure 1a and $\mathrm{b}$ show two examples of CloudSat IWC curtains at two random days, when one can see anvil and cirrus clouds associated with a tropical deep convection fanning out meridionally in the upper troposphere (Fig. 1a), while the clouds in the mid-latitude frontal system case apparently all tilt northward (Fig. 1b). DARDAR data (Fig. 2) are broadly consistent with those from CloudSat with some subtle differences. For example, DARDAR ice cloud product reveals a thin cirrus layer above the anvil clouds in the tropical deep convection case that is not detected by CloudSat.

To better understand the genesis of cloud tilt structures, we carried out mesoscale numerical simulations using the Weather Research and Forecasting (WRF) model in a tropical region. As a regional mesoscale model, WRF has been widely used for regional weather/climate studies and includes sophisticated cloud microphysics to represent the real atmosphere as well as possible (http://wrf-model.org). How-

\footnotetext{
${ }^{1}$ http://disc.sci.gsfc.nasa.gov/atdd/documentation/ ATrainTracks.pdf
} 

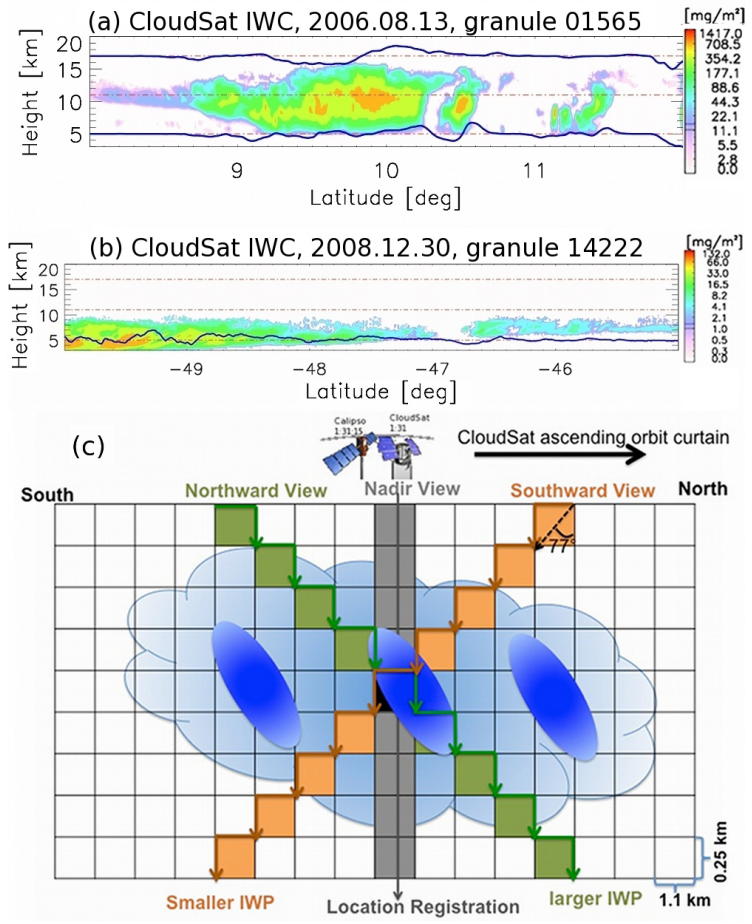

Figure 1. (a) and (b) show examples of ice water content (IWC) curtains from CloudSat 2B-CWC-RO product (V008). The curtains are divided into two sectors as indicated by the black dash-dotted lines. The color scale is linear with the largest (smallest) values in orange (white). The blue curves whose zero values are centered around the 5 and $17 \mathrm{~km}$ vertical levels illustrate the ice water path differences ( $\triangle \mathrm{IWP}$ ) derived from the algorithm demonstrated in the diagram (c) for layer 5-11 and 11-17 km. See text for details of (c) and the sign convention of the blue curves. The ratio is approximately $4: 1$ between horizontal and vertical scales for all panels; therefore, $77^{\circ}$ looks like $45^{\circ}$ in (c) because of the squeeze of the horizontal scale. Integration paths of the slantwise view are illustrated by green and orange arrows in (c).

ever, it is able to simulate the atmosphere for a much larger domain than cloud resolving models (CRMs). For the purpose of the current study, WRF simulations are designed to have a horizontal grid box $(\Delta L)$ of $3.3 \mathrm{~km}$ and a vertical resolution $(\Delta Z)$ of $\sim 0.5 \mathrm{~km}$ with cumulus parameterization turned off. As a result, WRF is used as a "cloud-resolving" model in a sense. The specific settings and simulation designs will be discussed in the next section.

In the CloudSat data analysis, we introduce a new approach for integrating the IWC measured along the orbital curtain (like that shown in Fig. 1). To mimic an "off-nadir" or "limb" viewing condition, we integrate the IWC profile along different slant paths by adding IWC at each unit volume (Fig. 1c). Therefore, in this analysis, without involving interpolation, each path has the same path length, and any differences between the IWCs integrated from different paths are due to cloud internal structural properties. This

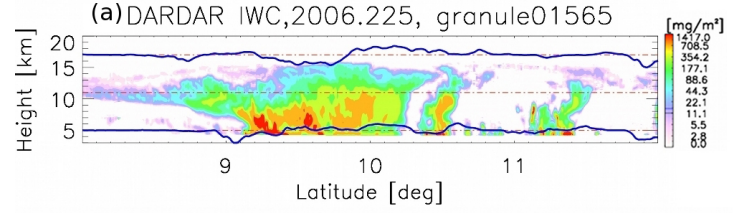

(b) DARDAR IWC,2008.364, granule 14222

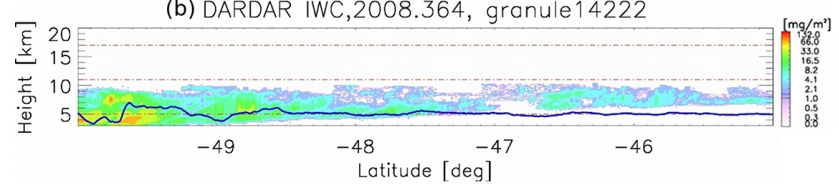

Figure 2. IWC curtains (color shading) from DARDAR-Cloud v2.1.1 retrieval products for the two cases shown in Fig. 1. Color scale is linear, and ranges between the maximum DARDAR IWC value within the curtain (red) and 0 (white). One can only find subtle differences in the IWC and $\triangle$ IWC (blue solid lines) values, but the clouds are in general more ubiquitous in the DARDAR product. For example, the DARDAR ice cloud product reveals a thin cirrus layer above the anvil clouds in the tropical deep convection case that is not detected by CloudSat.

slantwise integration of IWC, or ice water path, is the key concept in the current study. If the ice cloud density is randomly distributed along the horizontal direction or homogeneous inside a cloud, the IWP values integrated along the grey (nadir), orange (southward view, or S-view) and green (northward view, or $\mathrm{N}$-view) paths will show no differences. If the cloud ice tilts internally to the left, as shown by the blue ovals in Fig. 1c, the IWP along the green path will be the largest among the three paths. Hence, if we define $\Delta \mathrm{IWP}=\mathrm{IWP}_{\mid \mathrm{S} \text {-view }}-\mathrm{IWP}_{\mid \mathrm{N} \text {-view }}$, a positive (negative) $\triangle \mathrm{IWP}$ value means that the cloud tilts northward (southward). In Fig. 1a, the blue line at $17 \mathrm{~km}$ height, which represents $\triangle I W P$ integrated between 11 and $17 \mathrm{~km}$ with a viewangle of $77^{\circ}$, is negative at the south flank and positive at the north flank of the deep convections down below, which indicates an outward divergent flow. In Fig. 1b, the blue line at $5 \mathrm{~km}$ height, corresponding to $\Delta \mathrm{IWP}$ integrated between 5 and $11 \mathrm{~km}$ with the same view-angle, has a positive sign in most places, which translates to a systematic northward tilt of mid-level frontal clouds. These two real cases demonstrate the validity of our method. The same method is applied to WRF simulations to infer cloud tilt structures.

In theory, $\triangle$ IWP can be computed from different pairs of slantwise "scan angles". For example, in the case of Fig. 1c, the equivalent scan angle is $77^{\circ}$ as the tangent value of $77^{\circ}$ equals to the CloudSat grid box length / width ratio (i.e., tan $77^{\circ}=1.1 / 0.25 \mathrm{~km}$ ). The IWC profile is initially interpolated to $250 \mathrm{~m}$ vertically (roughly the original vertical resolution), and the slantwise IWP is then calculated by staggering every $1,2,3$ and 4 grids each time, which translates to a viewangle of 77, 65, 56 and $48^{\circ}$, respectively. Meanwhile, cloud count (CC) is also memorized should any positive IWC value appear on the corresponding slantwise path of mass integration. As CC is also different between paired slantwise paths, 
$\Delta \mathrm{IWP}$ is technically defined as $\frac{\sum \mathrm{IWP}_{\mid \mathrm{S} \text {-view }}}{\sum \mathrm{CC}_{\mid \mathrm{S} \text {-view }}}-\frac{\sum \mathrm{IWP}_{\mid \mathrm{N} \text {-view }}}{\sum \mathrm{CC}_{\mid \mathrm{N} \text {-view }}}$ to take such an impact into consideration. Results from the $77^{\circ}$ view-angle will be shown in the following section based on the fact that the resulting patterns remain largely robust for all four angle pairs. Since interpolation was not conducted along the slantwise path, neither interpolation-associated spurious signals nor a scan angle dependency exists. As tropical ice clouds usually extend from 5 to $17 \mathrm{~km}$ (Wu et al., 2009), the cloud structure is therefore divided into two equally thick layers for analysis: 5-11 and 11-17 km, in order to give them equal weight during the analysis process. The $11 \mathrm{~km}$ level also roughly separates the middle and upper troposphere at the tropics. In each layer, the cloud center of mass is assumed to be in the middle of the layer for the location registration (e.g., the location of the black box in Fig. 1c). The parallax issue (Marchand et al., 2007; Wu and Kayava, 2013) is mostly solved by this assumption through large sample integration. Furthermore, since $\triangle \mathrm{IWP}$ is computed instantaneously for slantwise and nadir views, the local time difference issue which is unavoidable for cross-track scanners is eliminated, although we can only infer the cloud meridional tilt structure here. The same method is likewise applied to the DARDAR product. This paper will focus on presenting the systematic cloud tilt structure in the UT between 11 and $17 \mathrm{~km}$ in the tropics. The results in the lower level, which has some limitations, will be shown for completeness.

Finally, Aura Microwave Limb Sounder (MLS) radiance $\left(T_{B}\right)$ data at $640 \mathrm{GHz}$ is used to illustrate the potential impact of our finding on satellite retrievals. The $640 \mathrm{GHz}$ channel has a weighting function peaking at tangent height $\sim 12 \mathrm{~km}$, and it is only sensitive to ice clouds. By averaging the 20 saturated radiance measurements at the bottom of each scan, we can treat the averaged radiance as those measured from the slant views by a nadir sounder rather than from a limb column, which helps distill the complex cloud information ( $\mathrm{Wu}$ and Eckermann, 2008). The MLS $640 \mathrm{GHz}$ forward-looking view has an even shallower viewing angle $\left(86^{\circ}\right)$. Therefore, by defining $\Delta T_{B}=T_{B_{\mid \text {night }}}-T_{B_{\mid \text {day }}}$, we can mimic the slantwise scan angle that is used to compute the CloudSat $\triangle$ IWP. However, MLS $\Delta T_{B}$ contains all-sky information from the cloud structure, cloud diurnal variation and other signals in the upper troposphere. Hence, the analysis results using MLS observation have to be interpreted with a lot of caution. Details will be discussed in Sect. 4 .

\section{Upper-troposphere cloud tilt in the tropics}

By differencing the CloudSat IWP in the upper troposphere (11-17 km) along the $77^{\circ}$ viewing angles (S-view minus $\mathrm{N}$-view), we found that UT ice cloud mass in the tropics tilted systematically poleward in both hemispheres, as shown in the left panel of Fig. 3 for the December-JanuaryFebruary (DJF) and right panel for the June-July-August (JJA) composites. The time separation roughly character- izes two broad tropical deep convective zones, namely South America, southern Africa and the western Pacific during DJF, and west of Central America, western Africa and the Asian Monsoon region including the Maritime Continent during JJA. The maps derived from ascending and descending orbits separately are highly similar to each other (not shown). Given the fact that CloudSat's orbit is not strictly perpendicular to the equator ( $82^{\circ}$ angle at the equator), any signal from the zonal direction projected to the orbit track would be with the opposite sign between the ascending and descending orbits. Therefore, the highly consistent geographic patterns between the day (ascending) and night (descending) imply that the signals should mainly originate from the meridional direction rather than the zonal direction. The relative importance of the mass asymmetry due to the systematic tilt, as measured by $\triangle \mathrm{IWP} / \mathrm{IWP}$, could easily reach up to $20 \%$ near the two flanks of the aforementioned tropical deep convective zones (Fig. 2c and d). The sign of the difference is consistent among all four view-angle pairs (not shown), except that the magnitude increases with increasing view angle values, indicating that the UT ice cloud mass is tilted in a very shallow angle with respect to the horizon $\left(\leq 90^{\circ}-77^{\circ}=13^{\circ}\right)$. However, these clouds are not completely flat, which should otherwise result in no difference of IWP between paired views. A similar analysis has also been carried out with DARDAR IWC profiles, and the patterns are highly consistent with those found from CloudSat except that the magnitude of the difference is slightly smaller while the relative importance remains the same order of magnitude (Fig. 4). This is to be expected for IWP as CloudSat alone can detect the majority of cloud ice. The broad consistency between CloudSat and DARDAR analysis results show the robustness of our findings.

From Figs. 3 and 4, we see that the patterns are more zonal during JJA than those during DJF, mainly because the continental deep convective centers are located further south during DJF than the latitude migration of the Intertropical Convergence Zones (ITCZs). The "upward-diverging" feature is not only ubiquitous to the tropics, but also present at the north and south flanks of mid-latitude summer active convection regions such as the Southern Pacific Convergence Zone (SPCZ) during DJF, and central United States and southern Europe during JJA, where deep convective towers often penetrate upward beyond the $11 \mathrm{~km}$ level. Note that the smoothing window is narrower in the top panels of Fig. 3 to highlight these mid-latitude details. The major reason that no signals were found from the rest of mid-latitude area is due to a shallower tropopause height there $(<11 \mathrm{~km})$. The same analyses were performed by truncating the mid-latitude troposphere into the $5-8$ and $8-11 \mathrm{~km}$ sectors. Systematic poleward tilt is discovered in the $8-11 \mathrm{~km}$ layer cloud in the winter mid-latitudes along storm tracks (not shown). Therefore, we should not interpret too much about the relative importance of maps in the mid-latitudes as the sample size is very limited above $11 \mathrm{~km}$. 

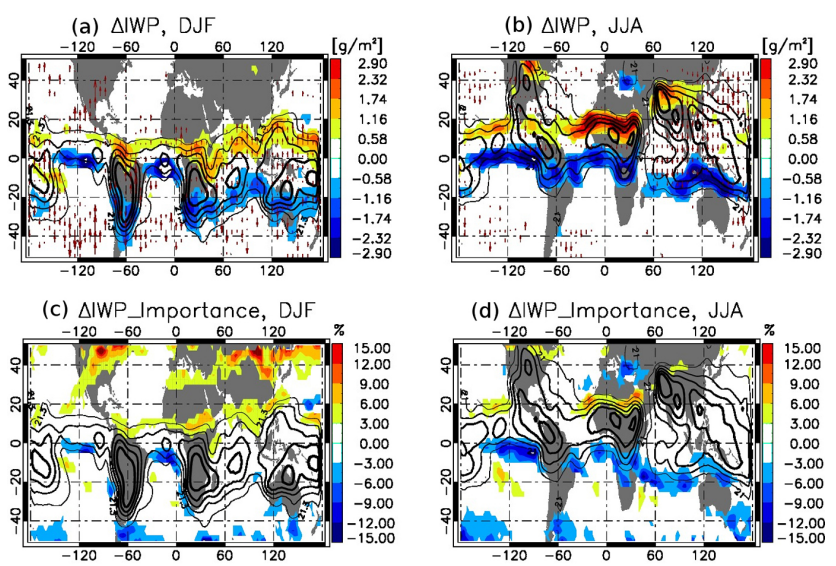

Figure 3. $\triangle \mathrm{IWP}$ (color shades; unit is $\mathrm{g} \mathrm{m}^{-2}$ ) between the south view and the north view with view-angle of $77^{\circ}$ for DecemberJanuary-February (a) and June-July-August (b) averaged during 2007-2010 between 11 and $17 \mathrm{~km}$. Results are based on CloudSat IWC data set within $\pm 50^{\circ}$ latitude range. The corresponding percentage difference of IWP (i.e., $\triangle$ IWP/IWP, color shades; unit is $\%$ ) is shown in (c) for DJF and (d) for JJA. The mean IWP within this altitude range is contoured in black with the contour interval equal to the minimum value shown on the contour line. Modern-Era Retrospective analysis for Research and Applications (MERRA) cloudy-sky meridional wind climatology during the same period is shown in arrow in (a) and (b) with wind speed linearly proportional to the arrow length. The longest arrow corresponds to $16 \mathrm{~m} \mathrm{~s}^{-1}$ in (a) and $9.15 \mathrm{~m} \mathrm{~s}^{-1}$ in (b). Data in the top panels are smoothed by a $2 \times 2$ smoothing window.

Intuitively, the systematic cloud tilt should be somewhat related to the local or general circulation. In the meridional direction at the tropics, the Hadley Cell dominates the tropospheric circulation, which has the convergence flow at the lower level in the tropics, and divergence flow at the upper level in the subtropics. In reality, the Hadley Cell has a complicated longitudinal structure. The cloudy-sky meridional wind derived from Modern-Era Retrospective analysis for Research and Applications (MERRA) analysis data sets is overlaid as arrows in Fig. 3a and $b$ to illustrate the divergent upper-level branch of the Hadley Cell circulation in most places over the tropics. Here, the cloudy-sky is defined as MERRA IWC larger than $10 \mathrm{mg} \mathrm{m}^{-3}$ anywhere between 11 and $17 \mathrm{~km}$ in altitude. The divergent flow is generally larger at the peripheries of the active tropical convective regions than that close to the centers, coinciding with the largest cloud asymmetry patterns. This suggests that the systematic UT cloud mass tilt does somewhat follow the general circulation in the meridional direction at the tropics. However, the meridional wind in the Asian Monsoon and Maritime Continents region during JJA is predominantly southward, while the UT cloud mass tends to tilt the same way as other regions in the tropics. The dominant southward flow in this area is associated with pan-continental-scale anti-cyclonic monsoon circulation, yet the cloud mass tilt is not controlled by this
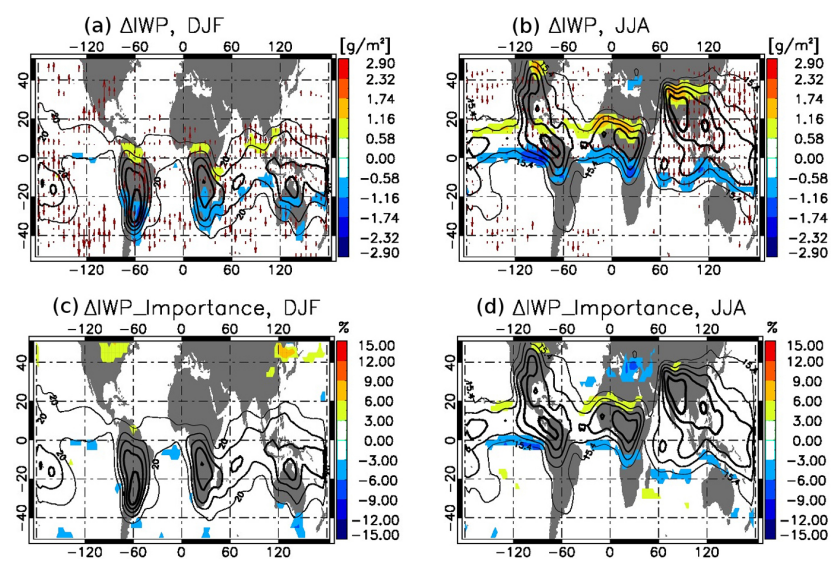

Figure 4. Same as Fig. 3, except using DARDAR v2.1.1 IWC product within the same altitude range.

large-scale circulation but still follows the Hadley-cell type of divergence flow pattern. More interestingly, the results suggest that UT cloud mass tilt does not follow the shape of the tropopause that slopes down away from the equator. The implications will be discussed in the next section. The meridional wind over central USA and southern Europe during JJA is very small and non-divergent, again indicating that the UT cloud tilt does not always follow the general circulation.

Ice cloud tilt in the middle troposphere $(5-11 \mathrm{~km})$ still has some ambiguities due to large uncertainties embedded in IWC retrievals below $9 \mathrm{~km}$ for heavily precipitating cases. The simplified assumption of IWC/liquid water content (LWC) partitioning of this data set in mixed-phase conditions contributes another big source of uncertainty. Even if we could exclude those cases, IWC itself cannot reveal the entire cloud mass/shape structure in the lower level as liquid and mixed-phase clouds dominate there (e.g., the rounded bottom of deep convective clouds of Fig. 1a between 9 and $10^{\circ} \mathrm{N}$ ). Preliminary results from CloudSat suggest that 5$11 \mathrm{~km}$ ice cloud mass at the tropics tilt the opposite way to that in the UT (i.e., equatorward, part of which will be shown in Fig. 6b), although the cloudy-sky wind at that altitude range is still weakly divergent in the broad picture as suggested by MERRA analysis and Multi-angle Imaging SpectroRadiometer (MISR) mid-level wind data sets (not shown). Meanwhile, mass tilt in this altitude range is barely statistically significant at a $95 \%$ confidence level as noted in DARDAR (not shown). Given the fact that the ice mass tilt in the middle troposphere is largely debatable, we will show using the WRF simulations that CloudSat results might be more reasonable.

As seen in Fig. 3d, the UT cloud tilt is relatively more important along the ITCZ cloud bands to the west of Central America and central Africa, while the situation is more complicated and less important in the Asian Monsoon region. Therefore, west of Central America (WCA), with a relatively simple surface condition, is an ideal region to conduct a nu- 


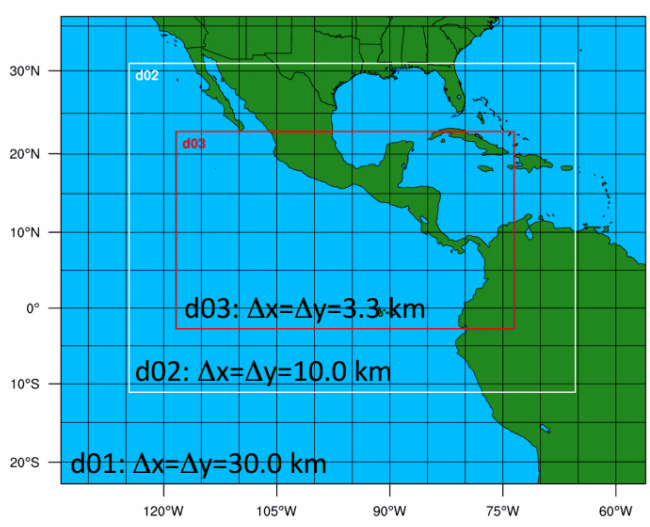

Figure 5. The domain map of WRF nested simulations.

merical experiment to investigate the underlying causes of the observed tilt.

In the WRF experiments, we randomly selected three days within 1 month to initialize the simulation $(1,15,30 \mathrm{Au}-$ gust 2009). Each simulation lasted for 2 days. The National Center for Environmental Prediction (NCEP) Global Forecast System (GFS) Final analyses (FNL) served as the boundary and initial conditions. In a nested configuration, the model has a primary domain (D01) with a $30 \mathrm{~km}$ horizontal resolution, a secondary domain (D02) with a $10 \mathrm{~km}$ horizontal resolution and the innermost domain (D03) with a $3.3 \mathrm{~km}$ horizontal resolution. Each nested domain is driven along the lateral boundary conditions supplied by the parent domain with coarse resolution. The domain map is shown in Fig. 5. The vertical resolution is roughly $500 \mathrm{~m}$ from the surface up to $50 \mathrm{hPa}$ (the model top). The inner domain boundary is $\left[118,77^{\circ} \mathrm{W} ; 2.5^{\circ} \mathrm{S}, 22.5^{\circ} \mathrm{N}\right]$. No damping of vertical motion or gravity wave is specified. As part of the provided microphysical scheme in WRF, the Morrison double moment scheme with forecast for six hydrometers in every time step was employed for all runs (Morrison et al., 2009). Since the cumulus parameterization has been turned off in D03, this configuration can reasonably capture the cloud vertical structure, despite the fact that clouds smaller than $24 \mathrm{~km}$ horizontally and $4 \mathrm{~km}$ vertically $(\sim 8 \times$ grid size) would be significantly under-resolved. Results from D02 with cumulus parameterization served as the sensitivity experiment to test whether realistic convection without subgrid-scale parameterization is the key to reproduce the observed cloud slantwise tilt. The hourly output from D02 and D03 was first interpolated to $250 \mathrm{~m}$ vertical and $1.1 \mathrm{~km}$ horizontal resolution and then analyzed and averaged together to represent the climatological mean condition.

Overall, D03 simulations show impressive agreement with CloudSat observation in terms of the geographical distributions of the mean IWP and the systematic ice cloud mass tilt in both the middle and upper troposphere. Given the fact that we are comparing 6-day simulations (with a hourly outputs; Fig. 6c and d) with 12 months of CloudSat overpass samples in the same region (Fig. 6a and b), the D03 simulations are good enough to qualitatively represent the climatological spatial patterns of middle-level converging and upper-level-diverging cloud mass tilt. The cloud structural inclination again fits the conceptual picture of flow convergence in the lower level and divergence in the upper level within the rising branch of the Hadley Cell. As the simulated mean IWP shows two centers of enhancement in the upper troposphere, the systematic "upward-diverging" cloud tilt structures occur at the north and south flanks of both centers separately (Fig. 6c). This feature again demonstrates that systematic cloud tilts in the UT always occur at the meridional peripheries of deep convective centers but not within the center.

In the middle troposphere, most ice clouds are convective cumulus. Some of previous case studies suggested that the tilt of convective core within a convective system could experience a life cycle of leaning downshear, upright and upshear with respect to the low-level wind shear (Weisman and Rotunno, 2004; Lane and Moncrieff, 2010). The climatological characteristic of the vertical orientation of deep convective cumulus has not been well studied nor understood at all. Both Fig. 6d observed by CloudSat and Fig. 6e simulated by WRF D03 experiment show generally opposite patterns to the UT ice clouds, so we can reach the conclusion that the mid-level ice cloud mass tends to exhibit a "converging" signature on a climatological mean. However, the discrepancy between DARDAR and CloudSat observations in the mid-level is still not explained. Also, the magnitude of $\triangle$ IWP is 5-10 times smaller in D03 simulation than that observed by CloudSat. The smaller $\triangle$ IWP in D03 may probably be attributed to the coarse model resolutions $(3.3 \mathrm{~km})$ that could not explicitly resolve enough details of the cloud structures. On the contrary, simulation results from D02 do not reproduce the observed mean IWP distribution and the mass asymmetries (Fig. 6e and f). Hence, we can conclude that the shutdown of cumulus parameterization (thereby, allowing the model to resolve clouds) is the key to successful generation of the systematic cloud mass tilts. In other words, realistic representation of convective processes is fundamental in capturing the cloud inhomogeneity.

UT systematic cloud tilt could introduce a non-trivial error to limb/sub-limb satellite retrievals of ice cloud mass. In this paragraph, we aim to check whether same issue could be present for ground instruments as well. To accomplish this, slantwise integration paths are now set to start from the ground (technically $3 \mathrm{~km}$ to avoid topography) upward and end at an altitude of $19 \mathrm{~km}$, and the cloud location is now registered at the starting point of integration. This is illustrated in Fig. 7. Note that the southward view still means looking southward, but opposite to the satellite-based view. This ground-based concept should be differentiated from the previous "satellite-based view" shown in Fig. 1c. Here, the focus is to study the impact from the systematic ice cloud tilt on ground instrument measurements, rather than the physics 


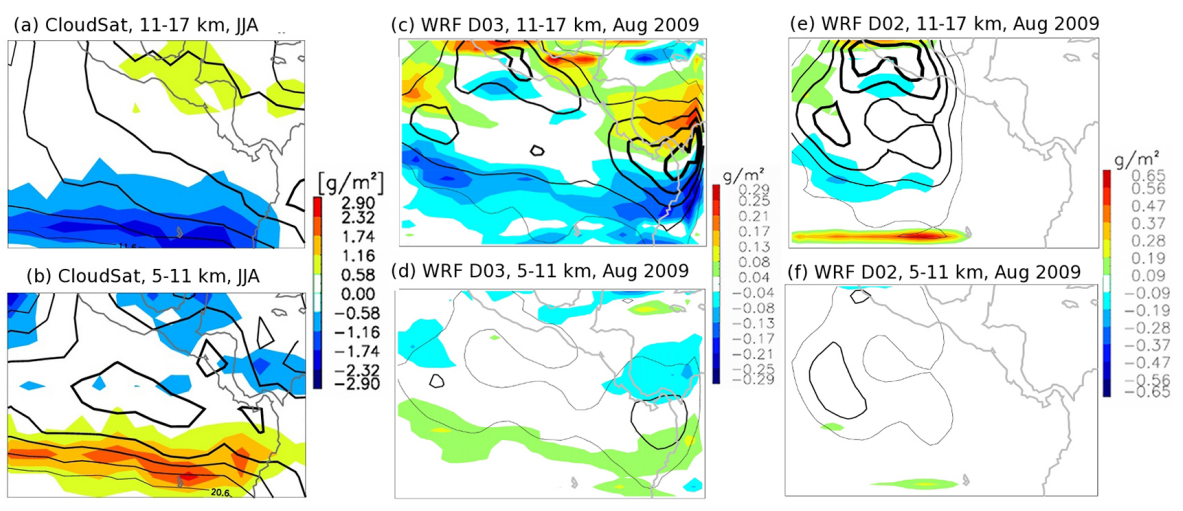

Figure 6. Climatological $\triangle$ IWP (color shades) derived from CloudSat at $77^{\circ}$ view angle during JJA, 2007-2010 for ice clouds within 11$17 \mathrm{~km}$ (a) and 5-11 km (b), and the same variable derived from WRF D03 (c and d) and D02 (e and f) domains at $77^{\circ}$ view angle. The black contours mark the mean IWP integrated along the nadir view within the corresponding altitude range. Note that the magnitude of $\Delta$ IWP from WRF run is much smaller than that from the CloudSat observations.

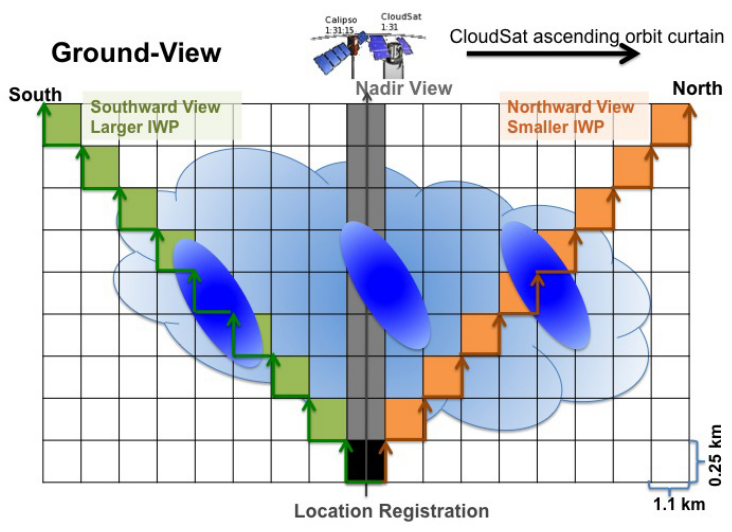

Figure 7. A diagram showing the computation geometry of the ground view.

of cloud vertical orientation. With this consideration, $19 \mathrm{~km}$ rather than $17 \mathrm{~km}$ was chosen as the ending point of mass integration since ice clouds rarely penetrate up beyond $19 \mathrm{~km}$. Figure 8 gives the IWP difference of ground-based view from four pairs of view-angle versus the nadir view (Fig. 8a) and $\triangle$ IWP between paired views computed from CloudSat data (Fig. 8b). Surprisingly, slantwise IWP is only slightly smaller than the nadir IWP; the largest discrepancy, observed at the most oblique views (equivalent to $76^{\circ}$ ) is only $4 \%$ of the mean IWP across all latitudes. This is mainly originated from a slightly larger cloud occurring frequency at oblique view angles. Through the total column integration, the south-north difference induced by the systematic cloud tilt is also trivial compared to nadir mean (Fig. 8b). However, if we integrate from $11 \mathrm{~km}$ upward to $19 \mathrm{~km}$ using the ground-base viewing geometry, the results look almost identical to Fig. 3 (not shown). This is somewhat expected since it is not fundamentally different from the satellite view shown in Fig. 1c, and parallax effect should only be important to the boundaries of
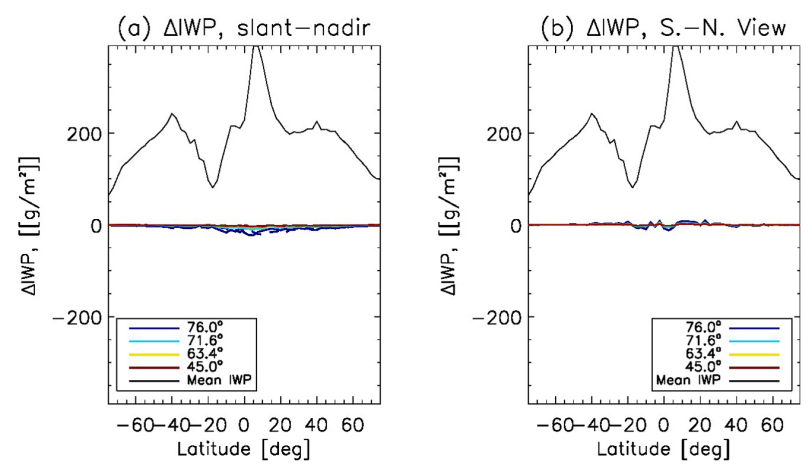

Figure 8. Ground-based view of (a) latitudinal distribution of JJA $\triangle$ IWP between nadir and southward-looking view (solid lines), nadir and northward-looking views (dashed lines with the same color of solid lines). (b) Latitudinal distribution of JJA $\triangle I W P$ between southward-looking and northward-looking views (solid color lines) integrated from 5 to $19 \mathrm{~km}$. The black solid lines are the mean IWP at nadir. See Fig. 7 for viewing geometry.

each grid box. As was explained and shown by Fig. $6 \mathrm{~b}$ and $\mathrm{d}$ before, mid-troposphere ice cloud tilt presents the opposite direction of its counterpart in the UT region. This groundbased view study reveals that their effects can be largely canceled out through the total column integration, and, therefore, we can conclude that systematic ice cloud tilt may not induce potential uncertainty to ground cloud measurements. Consequently, it is not a concern either for satellite nadir or nearnadir measurements that penetrate through the total column of atmosphere.

\section{Formation mechanism and importance of systematic UT cloud tilt}

CloudSat, DARDAR observations and WRF "cloudresolving" simulations all suggest that systematic UT cloud 
mass tilts tend to occur at the northern and southern peripheries of tropical deep convective regions. The corresponding cloudy-sky meridional wind climatology indicates that the observed/simulated systematic cloud tilt is likely associated with local large-scale divergent wind, which is a part of the Hadley Cell circulation. However, this explanation does not hold in the Asian Monsoon region, in the summer central United States or southern Europe, the latitudes of which beyond the reach of the rising branch of the Hadley Cell. More importantly, the largest systematic asymmetries do not occur near the most active convective centers where wind divergence is the largest. Besides, the upward sloping of UT cloud cannot be attributed to the meridional wind only. At $5-11 \mathrm{~km}$, Hadley circulation computed from the reanalysis wind is weakly divergent. Therefore, the possible $5-11 \mathrm{~km}$ ice cloud equatorward tilt cannot attributed to the general circulation, either. Our results suggest that the structural characteristics of UT clouds, including anvil and cirrus clouds, are not simply controlled by the large-scale general circulation. The local in-cloud circulation must be critical.

We propose the climatological adding and canceling effect as the major cause of the observed cloud tilt pattern. As depicted by the conceptual diagram in Fig. 9, each individual convective cloud or cloud system could form such an upward-diverging cloud structure at the upper-level due to mass and momentum continuity. Within the active convection centers such as the ITCZ belt, a myriad of individual convection/convective systems would lead to a large cancellation of the tilt effect, and only at the northernmost and southernmost flanks can we identify such a net adding effect of systematic cloud inclination. It is remarkable that the adding effect dominates over the canceling effect across such a wide latitude range $\left(5-10^{\circ}\right)$. This hypothesis may also explain the features occurring in the mid-latitude convective centers during summer seasons. The mid-level converging tilt, if real, may be also attributed to this adding and canceling effect assuming that the slantwise orientation of the convective core is determined by lower level wind below $5 \mathrm{~km}$. Further analysis of wind-cloud tilt relationship is required to confirm this hypothesis. Unfortunately, due to the lack and difficulty of in-cloud wind measurements, we cannot test this hypothesis in this paper. It is also of great interest to study details of the "in-cloud wind versus tilt angle" relationship that is possibly affected by other factors (e.g., CAPE, vertical velocity, different stage of cloud development, etc.).

Clearly, neglecting systematic cloud tilt in satellite retrieval can result in additional biases especially for limb sensors (e.g., Microwave Limb Sounder), nadir sensors at slantwise view-angles (e.g., AIRS, MODIS) and conical sensors (e.g., Clouds and the Earth's Radiant Energy System). For example, Gong and $\mathrm{Wu}(2011,2013)$ acknowledged the impact on AIRS cloudiness in the zonal direction, where they concluded that up to $50 \%$ of AIRS view-angle asymmetry could be attributed to the systematic westward-tilted cloud structures in the UT. Aura Microwave Limb Sounder (MLS)

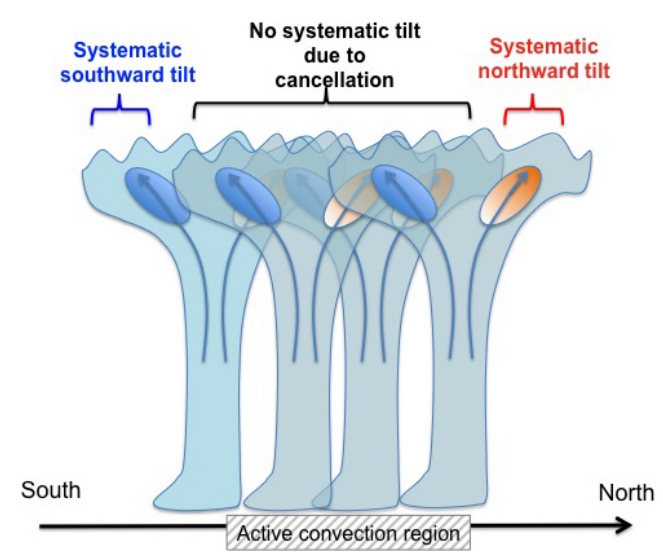

Figure 9. Schematic diagram showing the explanation of systematic poleward UT cloud tilts at the north and south peripheries of active tropical convection regions.

day (night) forward-looking view is analogous to CloudSat northward (southward) looking view with a shallower viewing angle $\left(\sim 86^{\circ}\right)$. Therefore, the cloud $\Delta T_{B}$ between MLS descending and ascending orbits contain mixed information from the cloud structures and cloud diurnal variation. This is a common issue for other cross-track sensors as well. Strikingly, the night and day radiance difference $\left(\Delta T_{B}\right)$ from MLS forward scan at $640 \mathrm{GHz}$ (peaking at $\sim 12 \mathrm{~km}$ ) has a high degree of agreement with the IWP difference derived from CloudSat observation in terms of geographic locations and magnitudes, as shown in Fig. 10. The highly consistent pattern strongly suggests that systematic cloud tilt contributes to a significant part of MLS $\Delta T_{B}$ signal. Based on our current study, the slantwise ice cloud mass orientation would result in errors of 5-20\% in IWP or IWC retrievals using an offnadir scan angle. The errors would be systematic at the north and south flanks of the tropical deep convective centers with a latitude width of $5-20^{\circ}$. The same order of magnitude of uncertainty would also be present inside the active convective centers when performing individual cloud profile retrieval, despite that the climatological impact is probably trivial due to the cancellation effect from large sampling. Hence, one should always be cautious of interpreting the ascendingdescending difference purely as cloud diurnal variations or "over-correcting" all angle-dependent cloud asymmetries as observational biases/artifacts.

The "against-tropopause shape" and "against-mean meridional wind" cloud mass tilt has strong implications on the dynamical impact of cloud associated momentum and energy transport. We found from this study that structural characteristics of anvil and cirrus clouds tended to be determined by in-cloud circulation rather than the prevailing general mean flow. Moreover, the UT ice cloud mass tilt seems not to be controlled by the low-level wind shear because it remains the same between CloudSat ascending and descending orbits when the mid-latitude summer convections are at differ- 


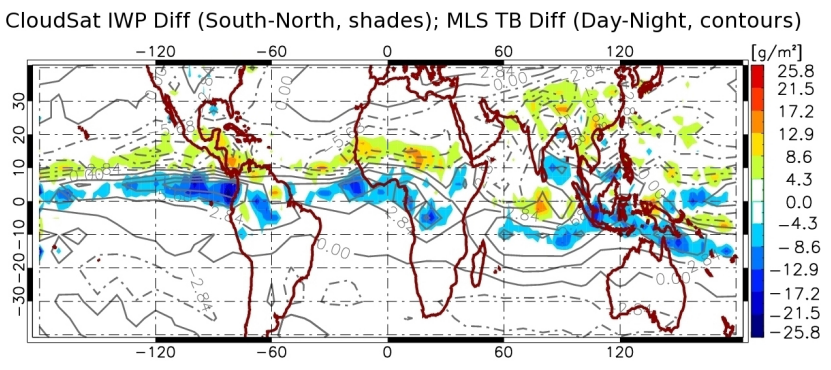

Figure 10. CloudSat $\triangle \mathrm{IWP}$ (color shades) and Aura MLS $640 \mathrm{GHz}$ $\Delta T_{B}$ (descending minus ascending orbits to mimic CloudSat viewing geometry, shown in contours; dashed is negative, solid is positive) for JJA, 2007-2010. The maps are interpolated to a $2^{\circ} \times 2^{\circ}$ grid box, and the correlation coefficient is -0.68 . Note that MLS has a shallower viewing angle, and it has a cloud diurnal cycle embedded in the signal.

ent stages (Weisman and Rotunno, 2004). Are cloud induced momentum and energy fluxes at the tropopause level particularly strong over the regions where the systematic cloud mass tilt is the most apparent? Cloud-resolving-scale modeling studies (beyond what has initially been done here) are required to answer such kind of questions.

This study also has some implications for CRE evaluation. Studies have shown that CRE in the UT region also affected the cross-tropopause mass transport of atmospheric constituents (Corti et al., 2006). Cloud inhomogeneity within satellite footprint has been treated with sophisticated schemes by some satellite observational teams (e.g., CERES) in the calculation of shortwave (SW) CRE, but the longwave (LW) CRE calculation has not taken the cloud vertical asymmetry into consideration so far (Loeb et al., 2005, 2007). Although thick clouds are opaque at IR band, thin clouds like cirrus are not. The IWP difference from observing a slantwise tilted cirrus at off-nadir views is expected to be positively correlated with TB difference at IR channels, causing an angle-dependent LW CRE estimation. Wu and Liang (2005) claimed that LW CRE was different by $8-16 \%$ between realistic vertical overlapping (i.e., vertical geometry) and the "maximum-random" assumption using a month-long cloud resolving simulation, which was on the same order of SW CRE uncertainty and in the same range as our estimation. Discrepancies among active and passive satellite sensors on the derived LW CRE may be partly attributed to the tilted cloud structures as well (Li et al., 2011). Cloud tilts also affect the precipitation/rain pattern. For example, Wu and Liang (2005) found that the estimates of surface rainfall were greatly improved when they switched the cloud-overlapping scheme from a standard option to a physical-based one.

\section{Conclusions}

By integrating and differencing CloudSat/DARDAR ice water content (IWC) along a pair of symmetric slant views, we find that tropical upper troposphere (UT, 11-17 km) ice cloud mass is ubiquitously tilted. The most prominent tilts occur in the north and south flanks of tropical deep convective centers such as the Asian Monsoon region and the ITCZs. The UT clouds in the tropics generally produce polewardtilted ice columns, rendering significant view-angle dependent cloud ice differences. The slant-view IWPs can differ by $5-20 \%$ from opposite scan angles, depending on what view angle is used. Cloud-resolving-scale WRF model simulations over the western Central American ITCZ showed good agreement with the CloudSat-observed cloud tilt structures at 11-17 km. Moreover, both CloudSat and WRF simulations suggest a mid-level $(5-11 \mathrm{~km})$ cloud mass converging tilt as well, while the total column integration of the oppositetilted structures largely cancel out the effects of each other. The mid-level tilt is still debatable due to large uncertainties associated with the limitation of W-band radar in precipitating scenes and mixed-phase scenes, and the coarse resolution of WRF simulations.

These cloud tilt characteristics are consistent with the convective outflow from tropical deep convection as a result of mass conservation. The constructively adding and canceling effect of a large ensemble of tilted cloud ice mass, driven by in-cloud circulation, can explain the geographic distribution of systematic cloud mass tilt. However, due to lack of accurate in-cloud wind measurements, the proposed hypothesis has not been verified and remains to be tested in the future study.

This study for the first time presents a global characterization of cloud tilt structures in the middle and upper troposphere. The observed IWP differences in the paired slant views have important implications for remote sensing and modeling of global cloud systems, including satellite retrieval of cloud properties, atmospheric momentum and energy budget, CRE calculation and modulation of the hydrological cycle. The study raises more questions than answers, notably the wind-tilt angle relationship, and potential impacts on energy, momentum and hydrological cycles. More importantly, as GCMs continue to improve their resolution (e.g., NICAM; Satoh et al., 2008), vertically tilted cloud structures will become explicitly resolved. The modeled cloud 3-D inhomogeneity is subject to verification against the observations as shown in this study.

Acknowledgements. This work is performed at the NASA Goddard Space Flight Center with support from the NASA NNH10ZDA001N-ESDRERR (Earth System Data Records Uncertainty Analysis) project. V. Limpasuvan was supported by the National Science Foundation (NSF) under grants AGS-1116123 and AGS-MRI-0958616 and the Coastal Carolina University Kerns Palmetto Professorship endowment. The CloudSat data processed 
and stored at Colorado State University is appreciated. All data from this study are available upon request by sending an email to the corresponding author.

Edited by: C. Hoose

\section{References}

Austin, R. T., Heymsfield, A. J., and Stephens, G. L.: Retrievals of ice cloud microphysical parameters using the CloudSat millimeter-wave radar and temperature, J. Geophys. Res., 114, D00A23, doi:10.1029/2008JD010049, 2009.

Cahalan, R. F., Ridgway, W., Wiscombe, W. J., Bell, T. L., and Snider, J. B.: The Albedo of Fractal Stratocumulus Clouds, J. Atmos. Sci., 51, 2434-2455, 1994.

Corti, T., Luo, B. P., Fu, Q., Vömel, H., and Peter, T.: The impact of cirrus clouds on tropical troposphere-to-stratosphere transport, Atmos. Chem. Phys., 6, 2539-2547, doi:10.5194/acp-6-25392006, 2006.

Delanoe, J. and Hogan, R. J.: Combined CloudSat-CALIPSOMODIS retrievals of the properties of ice clouds, J. Geophys. Res., 115, D00H29, doi:10.1029/2009JD012346, 2010.

Delanoe, J., Protat, A., Jourdan, O., Pelon, J., Papazzoni, M., Dupuy, R., Gayet, J. F., and Jouan, C.: Comparison of airborne in-situ, airborne radar-lidar, and spaceborne radar-lidar retrievals of polar ice cloud properties sampled during the POLARCAT Campaign, J. Atmos. Ocean. Tech., 30, 57-73, doi:10.1175/JTECH-D-11-00200.1, 2013.

Eliasson, S., Holl, G., Buehler, S. A., Kuhn, T., Stengel, M., Iturbide-Sanchez, F., and Johnston, M.: Systematic and random errors between collocated satellite ice water path observations, J. Geophys. Res., 118, 1-14, 2013.

Fu, Q., Carlin, B., and Mace, G.: Cirrus horizontal inhomogeneity and OLR bias, Geophys. Res. Lett., 27, 3341-3344, 2000.

Gong, J. and Wu, D. L.: View-angle dependent AIRS cloud radiances: Implications for tropical anvil structures, Geophys. Res. Lett., 38, L14802, doi:10.1029/2011GL047910, 2011.

Gong, J. and Wu, D. L.: View-angle dependence of AIRS cloudiness and radiance variance: Analysis and interpretation, J. Geophys. Res., 118, 2327-2339, doi:10.1002/jgrd.50120, 2013.

Hong, G., Heygster, G., Miao, J., and Kunzi, K.: Potential to estimate the canting angle of tilted structures in clouds from microwave radiances around $183 \mathrm{GHz}$, IEEE Geosci. Remote Sens., 2, 40-44, 2005.

Huang, D., Zhao, C., Dunn, M., Dong, X., Mace, G. G., Jensen, M. P., Xie, S., and Liu, Y.: An intercomparison of radarbased liquid cloud microphysics retrievals and implications for model evaluation studies, Atmos. Meas. Tech., 5, 1409-1424, doi:10.5194/amt-5-1409-2012, 2012.

Lane, T. P. and Moncrieff, M. W.: Characterization of momentum transport associated with organized moist convection and gravity waves, J. Atmos. Sci., 67, 3208-3225, 2010.

Li, J. and Barker, H. W.: Accounting for unresolved clouds in a 1D infrared radiative transfer model. part I: solution for radiative transfer, including cloud scattering and overlap, J. Atmos. Sci., 59, 3302-3320, 2002.

Li, J. M., Yi, Y. H., Minnis, P., Huang, J. P., Yan, H. R., Ma, Y. J., Wang, W. C., and Ayers, J. K.: Radiative effect differ- ences between multi-layered and single-layer clouds derived from CERES, CALIPSO, and CloudSat data, J. Quant. Spectrosc. Ra., 112, 361-375, 2011.

Loeb, N. G., Kato, S., Loukachine, K., and Manalo-Smith, N.: Angular distribution models for top-of-atmosphere radiative flux estimation from the Clouds and the Earth's Radiant Energy System instrument on the Terra satellite. Part I: Methodology, J. Atmos. Ocean. Tech., 22, 338-351, 2005.

Loeb, N. G., Kato, S., Loukachine, K., Manalo-Smith, N., and Doelling, D. R.: Angular distribution models for top-ofatmosphere radiative flux estimation from the Clouds and the Earths Radiant Energy System instrument on the Terra satellite. Part II: Validation, J. Atmos. Ocean. Tech., 24, 564-584, 2007.

Marchand, R. T., Ackerman, T. P., and Moroney, C.: An assessment of Multiangle Imaging Spectroradiometer (MISR) stereoderived cloud top heights and cloud top winds using groundbased radar, lidar, and microwave radiometers, J. Geophys. Res., 112, D06204, doi:10.1029/2006JD007091, 2007.

Marshak, A., Platnick, S., Várnai, T., Wen, G., and Cahalan, R. F.: Impact of three-dimensional radiative effects on satellite retrievals of cloud droplet sizes, J. Geophys. Res., 111, D09207, doi:10.1029/2005JD006686, 2006.

Ming, M. and Zhang, Z.: On the influence of cloud fraction diurnal cycle and sub-grid cloud optical thickness variability on all-sky direct aerosol radiative forcing, J. Quant. Spectrosc. Ra., 142, 25-36, doi:10.1016/j.jqsrt.2014.03.014, 2014.

Morrison, H., Thompson, G., and Tatarskii, V.: Impact of Cloud Microphysics on the Development of Trailing Stratiform Precipitation in a Simulated Squall Line: Comparison of One- and Two-Moment Schemes, Mon. Weather Rev., 137, 991-1007, doi:10.1175/2008MWR2556.1, 2009.

Naud, C. M., Del Genio, A. D., Bauer, M., and Kovari, W.: Cloud vertical distributions across warm and cold fronts in CloudSatCALIPSO data and a general circulation model, J. Climate, 23, 3397-3415, 2010.

Oreopoulos, L., Lee, D., Sud, Y. C., and Suarez, M. J.: Radiative impacts of cloud heterogeneity and overlap in an atmospheric General Circulation Model, Atmos. Chem. Phys., 12, 9097-9111, doi:10.5194/acp-12-9097-2012, 2012.

Protat, A., Bouniol, D., Dalanoe, J., O’Connor, E., May, P. T., PlanaFattori, A., and Hasson, A.: Assessment of CloudSat reflectivity measurements and ice cloud properties using ground-based and airborne cloud radar observations, J. Atmos. Ocean. Tech., 26, 1717-1741, 2009.

Satoh, M., Matsuno, T., Tomita, H., Miura, H., Nasuno, T., and Iga, S.: Nonhydrostatic icosahedral atmospheric model (NICAM) for global cloud resolving simulations, J. Comput. Phys., 227, 34863514, doi:10.1016/j.jcp.2007.02.006, 2008.

Weisman, M. L. and Rotunno, R.: A theory for strong long-lived squall lines re- visted, J. Atmos. Sci., 61, 361-382, 2004.

Wu, D. L. and Eckermann, S. D.: Global Gravity Wave Variances from Aura MLS: Characteristics and Interpretation, J. Atmos. Sci., 65, 3695-3718, doi:10.1175/2008JAS2489.1, 2008.

Wu, D. L. and Kayava, M. J.: CGMS working paper global wind measurements from earth orbit - atmospheric motion vectors and development of Doppler Lidar Systems, CGMS-41 NASA-WP05, 2013.

Wu, D. L., Austin, R. T., Deng, M., Durden, S. L., Heymsfield, A. J., Jiang, J. H., Lambert, A., Li, J.-L., Livesey, N. J., McFarquhar, 
G. M., Pittman, J. V., Stephens, G. L., Tanelli, S., Vane, D. G., and Waliser, D. E.: Comparisons of global cloud ice from MLS, CloudSat, and other correlative data sets, J. Geophys. Res., 114, D00A24, doi:10.1029/2008JD009946, 2009.

$\mathrm{Wu}, \mathrm{X}$. Q. and Liang, X.-Z.: Radiative effects of cloud horizontal inhomogeneity and vertical overlap identified from a month-long Cloud-Resolving Model simulation, J. Atmos. Sci., 62, 41054112, 2005.
Yuan T. and Oreopoulos, L.: On the global character of overlap between low and high clouds, Geophys. Res. Lett., 40, 5320-5326, doi:10.1002/grl.50871, 2013. 